\title{
Reflections on common medication reconciliation practices impacting a case of discounted thyroid replacement hormone
}

\author{
Christopher Trautman, Jed C. Cowdell, Nancy Dawson, Michael Maniaci* \\ Department of Internal Medicine, Mayo Clinic, Jacksonville, FL, USA
}

Received: October 28, 2015

DOI: $10.5430 /$ crim.v3n1p29
Accepted: December 4, 2015 Online Published: December 10, 2015

URL: http://dx.doi.org/10.5430/crim.v3n1p29

\begin{abstract}
Quality problem or issue: Medication errors related to reconciliation processes.

Initial assessment: Even though most US medical centers utilize medication reconciliation processes to reduce medical errors, adverse events related to medications continue to occur causing extra burden on the US healthcare system. New strategies to reduce medication errors are being implemented, including pharmacy-based medication reconciliations.

Case report: An 86-year-old female was admitted for symptomatic bradycardia in the setting of a fall. During her hospitalization, she was evaluated for pacemaker implantation until her thyroid-stimulating hormone blood test revealed severe hypothyroidism. Medication reconciliation had been performed twice with the patient, and her family adamantly affirmed the patient was compliant on her levothyroxine. Upon further investigation, she had changed pharmacies nine months prior to her hospitalization and was obtaining her thyroid replacement hormone from an online Canadian pharmacy. Once restarting Synthroid, her symptoms improved allowing her to forego the procedure.

Lessons learned: Physicians must understand common pitfalls with rapidly verifying home medications against electronic medical records as patient knowledge of their home therapies is often inaccurate in combination with non-updated electronic data. Hospitals are evaluating strategies such as pharmacy-based medication reconciliations to reduce adverse events related to medication errors, which can decrease hospital costs and improve patient outcomes. Knowing which pharmacy is dispensing the medications can prove useful as discounted medications from online pharmacies may lack efficacy.
\end{abstract}

Key Words: Medication reconciliation, Medication errors, Levothyroxine, Drug efficacy

\section{INTRODUCTION}

Adverse drug events are common and potentially harmful to patients in addition to costing the United States approximately $\$ 3.5$ billion annually. ${ }^{[1,2]}$ Most medical centers perform a medication reconciliation to compare all active medications used by the patient with documented medications and prevent drug-drug interactions upon administering medications at time of treatment. ${ }^{[3]}$ This method has been proven to reduce medication errors and endorsed by multiple groups, including the U.S. Joint Commission for Accreditation of Healthcare Organizations and World Health Organization. ${ }^{[4,5]}$ Unfortunately, medication reconciliations are not accurately obtained for a multitude of reasons, including unfamiliarity by the patient/family regarding medications,

\footnotetext{
*Correspondence: Michael Maniaci, MD; Email: Maniaci.michael@ mayo.edu; Address: Mayo Clinic, 4500 San Pablo Ave, Jacksonville, FL 32224, USA.
}

Published by Sciedu Press 
computer errors, polypharmacy, and limited time available to complete a full reconciliation. ${ }^{[6]}$ We present here a case report showing the importance of a complete medication reconciliation and how interventions and management can be impacted by a single medication.

\section{CASe PResentation}

An 86-year-old female with history of chronic kidney disease, bipolar disorder, hypothyroidism, and hypertension presented to the emergency department after a fall. The patient recalled walking towards the kitchen and feeling unsteady on her feet. She went to reach for a countertop as she recognized she was falling, but was unable to support herself. She landed on a carpeted surface hurting her right knee. She denied head trauma, loss of consciousness, loss of bowel/bladder control, or biting her tongue. Her son detailed several similar falls over the past six months due to lower extremity weakness. She had been seen by neurology, who recommended physical therapy for improved physical conditioning. Associated with her fall, the son detailed increased confusion over the previous 24 hours, stating she was making confused statements. Upon reviewing her medications, no recent adjustments had been made and she was compliant on all of her medications. She continued to take amlodipine for blood pressure, levothyroxine for hypothyroidism, and olanzapine/sertraline for mood stabilization. She noted taking melatonin to sleep at night, but denied any benzodiazepine/antihistamine products. She had no prior history of baseline dementia. Review of systems was positive for intermittent dizziness/unsteadiness, lower extremity weakness, and difficulty sleeping. The patient denied recent illness, fevers, shortness of breath, palpitations, gastrointestinal symptoms, bleeding, skin rashes, tremor, or vertigo.

In the emergency department, the patient was found to be bradycardic with a resting heart rate ranging $45-55 \mathrm{bpm}$, but otherwise, vital signs were within normal limits. On exam, she was well nourished, alert, and oriented without any distress. Pertinent findings included a grade $2 / 6$ systolic murmur in the aortic region, no carotid bruits, $4 / 5$ lower extremity strength bilaterally, limited range of motion of the right knee due to trauma without swelling, and signs of poor short-term memory as she would repeat questions. Blood pressure was not orthostatic. Her initial laboratory findings showed reduced glomerular filtration rate at baseline, hypomagnesaemia, hypokalemia, and slight anemia. The electrocardiogram $(\mathrm{EKG})$ revealed sinus bradycardia with a 1 st degree atrioventricular block with a lengthening PR interval changed from an EKG obtained six months prior. No acute pathology was seen on her chest imaging. Cardiology was consulted to further investigate her bradycardia. Initially, her olanzapine was held due to concerns with improper home dosing and adverse effect of hypotension and syncope. While observing the patient over the weekend, no change was seen in her heart rate and an echocardiogram showed diastolic dysfunction with a preserved ejection fraction. On hospital day three, cardiac electrophysiology was consulted for pacemaker placement given signs of symptomatic bradycardia. Prior to taking the patient into the interventional suite, a pending thyroid-stimulating hormone (TSH) level came back as $98.4 \mathrm{mIU} / \mathrm{L}$ (normal $0.30-4.20 \mathrm{mIU} / \mathrm{L}$ ), indicating severe hypothyroidism. The patient's previous TSH from one year prior was $4.66 \mathrm{mIU} / \mathrm{L}$, with numerous stable readings evident from preceding years. Subsequent free T4 and total T3 were both found to be low.

Upon reinvestigating the patient's medication history, both the patient and her son affirmed that she was compliant on her levothyroxine, and the dose had not changed in many years. However, the son mentioned a change in pharmacy for her thyroid hormone supplementation. Approximately 9 months prior, he researched a low-cost online pharmacy based out of Canada dispensing levothyroxine at half the cost of his local pharmacy. Given her newly diagnosed uncontrolled hypothyroidism, she was given IV thyroxine, which facilitated improvement in her heart rate over the next 24-48 hours. She was discharged without cardiac device placement to a short-term rehabilitation facility with follow-up thyroid studies ordered.

\section{Discussion}

For this case, a medication reconciliation was performed twice, once in the emergency department and repeated upon admission. Both reconciliations accurately reflected the medications being used at home by the patient, yet an error still occurred, causing delay in appropriate management. A full medication reconciliation can take up to twenty minutes in order to obtain a full chart review and medication history interview and facilitate the necessary documentation and interventions. ${ }^{[7]}$ However, most physician performed reconciliations take less than ten minutes as constraints on time limit the ability to investigate all details related to medication history. Furthermore, there is inherent confusion among staff members regarding who should perform the reconciliation. Lee and colleagues paneled attending physicians, resident physicians, pharmacists, and nurses regarding who is responsible for medication history at time of admission. Their study showed an unclear expectation for each paneled group resulting in no clear consensus for accountability of completing the task. ${ }^{[8]}$

One solution proposed by van dem Bemt and colleagues suggests implementation of pharmacy-based medication rec- 
onciliations in substitution of physician-obtained reconciliations. ${ }^{[9]}$ Studies looking at physician verses pharmacist obtained reconciliations in the emergency department favored pharmacy-based reconciliations as pharmacists had a significantly lower number of discrepancies per patient and reductions in adverse drug events leading to improved patient safety. ${ }^{[10,11]}$ The most common discrepancies involved drug or dose omissions. Although pharmacists are reconciling the medications, physicians must review and approve the completed reconciliation. Community hospitals would need available resources in the pharmacy department to execute this strategy, including the availability of pharmacists to complete the task on all patient encounters. Several models have projected cost-savings with use of pharmacy-based reconciliations to equate around $300 \%$ return on investment for the new staff member. ${ }^{[7]}$ Given the training environment, university hospitals tend to have more available personnel to perform reconciliations, but medications errors can occur due to lack of familiarity with drugs or limited experience within a health system.

As for this patient's drug discrepancy, several drug classes have been labeled as problematic when substituting generic drugs for brand name drugs. In particular, thyroid substitutions, anticonvulsants, and conjugated estrogens have been studied revealing non-equivalence in bioavailability and/or efficacy. ${ }^{[12]}$ Due to a history of confounding evidence related to L-thyroxine (LT4) equivalency among competing interests, the Food and Drug Administration passed legislation in 1997 requiring manufacturers of LT4 to seek new drug approval in order to evaluate performance of each preparation. ${ }^{[13]}$ This addresses the narrow therapeutic window of the drug in addition to looking at shelf-life standardizations; however, a lack of viable evidence still remains related to safety of substituting generic formulations for brand names. ${ }^{[14]}$ Because of this, multiple societies, including the American Association of Clinical Endocrinologists, The Endocrine Society, and American Thyroid Association, have signed a joint statement recommending physicians educate their patients on monitoring pharmacy substitutions, maintaining the same preparation of LT4, and understanding the necessity of TSH testing when making adjustments to dosing. ${ }^{[14,15]}$

Although quickly verifying home medications against electronic medical records seems time efficient and complete, physicians must understand common pitfalls with this method as patient knowledge of their home therapies is often inaccurate in combination with non-updated electronic data. Hospitals are evaluating strategies such as pharmacy-based medication reconciliations to reduce adverse events related to medication errors, which can decrease hospital costs and improve patient outcomes. As seen in this case, knowing which pharmacy is dispensing the medicines can prove useful for determining the efficacy of medication. Not all medications are formulated equal, especially as patients are seeking discounted medications from online pharmacies.

\section{REFERENCES}

[1] Morimoto T, Sakuma M, Matsui K, et al. Incidence of adverse drug events and medication errors in Japan: the JADE study. J Gen Intern Med. 2011; 26: 148-53. PMid:20872082 http://dx.doi .org/10. $1007 /$ s11606-010-1518-3

[2] Aljadhey H, Mahmoud MA, Mayet A, et al. Incidence of adverse drug events in an academic hospital: a prospective cohort study. Int J Qual Health Care. 2013; 25: 648-55. PMid:24141014 http://dx.doi.org/10.1093/intqhc/mzt075

[3] Rogers G, Alper E, Brunelle D, et al. Reconciling medications at admission: safe practice recommendations and implementation strategies. Jt Comm J Qual Patient Saf. 2006; 32: 37-50. PMid:16514938

[4] Using medication reconciliation to prevent errors. The Joint Commission International. Available from: http://www.jointcommissio n.org/assets/1/18/SEA_35.PDF

[5] High 5s: Action on Patient Safety. World Health Organization. Available from: http://www.who.int/patientsafety/implemen tation/solutions/high5s/ps_med_rec_fs_Mar_2011.pdf

[6] Tam VC, Knowles SR, Cornish PL, et al. Frequency, type and clinical importance of medication history errors at admission to hospital: a systematic review. CMAJ. 2005; 173: 510-5. PMid:16129874 http://dx.doi.org/10.1503/cmaj.045311

[7] Chapter 1: Building the Project Foundation: Gaining Leadership Support Within the Organization: Medications at Transitions and
Clinical Handoffs (MATCH) Toolkit for Medication Reconciliation. Rockville, MD: Agency for Healthcare Research and Quality. Available from: http://www.ahrq.gov/professionals/qua lity-patient-safety/patient-safety-resources/resou rces/match/match1.html

[8] Lee KP, Hartridge C, Corbett K, et al. "Whose job is it, really?" Physicians', nurses', and pharmacists' perspectives on completing inpatient medication reconciliation. J Hosp Med. 2015; 10: 184-6. PMid:25408285 http://dx.doi.org/10.1002/jhm. 2289

[9] van den Bemt PM, van der Schrieck-de Loos EM, van der Linden C, et al. Effect of medication reconciliation on unintentional medication discrepancies in acute hospital admissions of elderly adults: a multicenter study. J Am Geriatr Soc. 2013; 61: 1262-8. PMid:23869999 http://dx.doi.org/10.1111/jgs. 12380

[10] Etchells E, Koo M, Daneman N, et al. Comparative economic analyses of patient safety improvement strategies in acute care: a systematic review. BMJ Qual Saf. 2012; 21: 448-56. PMid:22523319 http://dx.doi.org/10.1136/bmjqs-2011-000585

[11] Johnston R, Saulnier L, Gould O. Best possible medication history in the emergency department: comparing pharmacy technicians and pharmacists. Can J Hosp Pharm. 2010; 63: 359-65. http://dx.doi.org/10.4212/cjhp.v63i5.947

[12] Ross MB. Status of generic substitution: problematic drug classes reviewed. Hosp Formul. 1989; 24: 441-479. 
[13] Prescription drug products; levothyroxine sodium. Office of the Federal Register. 1997: 43535-8.

[14] Hennessey JV. Generic vs name brand L-thyroxine products: interchangeable or still not? J Clin Endocrinol Metab. 2013; 98: 511-4 PMid:23390262 http://dx.doi.org/10.1210/jc.2012-4310
[15] Joint position statement on the use and interchangeability of thyroxine products. American Association of Clinical Endocrinologists. Available from: https://www . aace.com/files/positio n-statements/aace-tes-ata-thyroxineproducts.pdf 